\title{
PHÁT TRIỂN DU LỊCH GẮN VỚI CHIẾN LỰ̛̣C MARKETING ĐỊA PHƯƠNG TẠI TỈNH TUYÊN QUANG
}

\author{
Develop tourism in association with the local marketing strategy in Tuyen Quang province
}

Ngày nhận bài: 04/05/2016; ngày phản biện: 12/5/2016; ngày duyệt đăng: 21/11/2016

Trần Thị Kim Oanh*

\section{TÓM TÁ̀T}

Marketing địa phương đang dần trở thành nhân tố quan trọng trong chiến lược phát triển của mỗi ngành, mỗi địa phương, mỗi quốc gia. Đây là hoạt động góp phần quảng bá hình ảnh, tạo ra sản phẩm có sức cạnh tranh nhằm thỏa mãn nhu cầu và tăng sức hấp dẫn của địa phương đó đối với khách hàng mục tiêu. Tuyên Quang là một tỉnh miền núi phía Bắc, với lợi thế về tài nguyên thiên nhiên, cảnh quan và con người, tỉnh Tuyên Quang có rất nhiều tiềm năng trong phát triển du lịch. Tuy nhiên, đến nay du lịch Tuyên Quang chưa thực sự tương xứng với tiềm năng và lợi thế đó. Bài viết này trình bày nghiên cứu về thực trạng marketing địa phương, từ đó đưa ra một số gợi ý chiến lược marketing địa phương nhằm phát triển du lịch cho tỉnh Tuyên Quang.

Từ khóa: Marketing địa phwơng; hoạt động marketing; chiến luợc marketing dịa phưong; du lịch Tuyên Quang

ABSTRACT

Local marketing has been gradually becoming an important factor in the development strategy of each sector, each province and each country. This activity is to contribute to promoting image, creating competitive products to meet demand and to increase attractiveness of localities for their targeted customers. Tuyen Quang is a mountainous province in the North with advantages of its natural resources, landscape and people. Thus, Tuyen Quang has great potential for tourism development. To date, Tuyen Quang's tourism industry, however, is not really commensurate with its potential and advantages. This paper seeks to study the situation of Tuyen Quang's local marketing. From the research results, it puts forward some suggestions for local marketing strategies to contribute to development of Tuyen Quang's tourism industry.

Keywords: Local marketing; marketing activities; local marketing strategies; Tuyen Quang's tourism industry.

\section{Mở đầu}

\section{1. Đặt vấn đề}

Xu hướng toàn cầu hóa nền kinh tế hiện nay đặt ra cho mỗi quốc gia, mỗi vùng lãnh thổ, mỗi địa phương những cơ hội và thách thức để đạt được sự phát triển đồng bộ và bền vững. Đối với nhiều quốc gia trên thế giới, du lịch đang trở thành ngành kinh tế mũi nhọn, chiếm tỷ trọng ngày càng cao trong cơ cấu
GDP, tạo động lực thúc đẩy phát triển kinh tế xã hội. Thông qua các hoạt động marketing địa phương, có thể xác định chính xác những mong đợi hiện tại hay tiềm năng của du khách, nhà đầu tư, người dân và các doanh nghiệp của địa phương đối với ngành du lịch. Nhiều quốc gia đã vận dụng lý thuyết về marketing địa phương để xây dựng thương hiệu, định vị hình ảnh dựa trên các chiến lược và chương trình

* Thạc sĩ - Trường Đại học Tân Trào 
marketing hiệu quả như Thái Lan, Singapore, Hàn Quốc. Các địa phương của Việt Nam cũng đang chú ý đến các hoạt động marketing nhằm quảng bá hình ảnh, thu hút khách du lịch như Quảng Ninh, Đà Nẵng, Thành phố Hồ Chí Minh. Có thể thấy, marketing đóng vai trò quan trọng trong chiến lược phát triển kinh tế xã hội và mỗi địa phương cần xây dựng cho mình chiến lược marketing địa phương nhằm phát huy thế mạnh của riêng địa phương đó.

Tuyên Quang được biết đến với những khu du lịch nổi tiếng như Khu di tích Quốc gia đặc biệt Tân Trào, khu du lịch suối khoáng Mỹ Lâm, khu du lịch sinh thái Nà Hang, gắn liền với các lễ hội mang đậm bản sắc dân tộc, độc đáo, tạo dấu ấn trong lòng du khách như lễ hội thành Tuyên, lễ hội Lồng Tông, lễ hội Giếng Tanh,... Nằm giữa các khu du lịch nổi tiếng như: Hồ Núi Cốc (Thái Nguyên), Hồ Ba Bể (Bắc Kạn), Cao nguyên đá Đồng Văn (Hà Giang) nên Tuyên Quang có nhiều lợi thế trong việc liên kết phát triển du lịch bên cạnh phát huy thế mạnh riêng có của mình.

Với những ưu thế trên, Tuyên Quang cần xây dựng chiến lược marketing địa phương nhằm phát triển du lịch. Kết quả của hoạt động này sẽ giúp tỉnh Tuyên Quang định vị và quảng bá hình ảnh tới khách du lịch, nhà đầu tư trong và ngoài nước, nhanh chóng trở thành một tỉnh phát triển mạnh về du lịch.

\subsection{Mục tiêu nghiên cứu}

Nghiên cứu này nhằm hệ thống hóa những lý luận cơ bản về chiến lược marketing địa phương. Phân tích và đánh giá thực trạng hoạt động marketing địa phương trong phát triển du lịch của tỉnh Tuyên Quang giai đoạn 2011 - 2015, từ đó đưa ra gợi ý chiến lược marketing địa phương và đề xuất các biện pháp nhằm tổ chức thực hiện các chiến lược cho tỉnh Tuyên Quang.

\subsection{Phương pháp nghiên cứu}

Nguồn số liệu thứ cấp sử dụng trong nghiên cứu được thu thập và tổng hợp từ niên giám thống kê, quy hoạch tổng thể phát triển du lịch tỉnh Tuyên Quang, các quyết định của Ủy ban nhân dân tỉnh và một số văn bản của Sở Văn hóa, Thể thao và Du lịch, Trung tâm xúc tiến đầu tư tỉnh Tuyên Quang liên quan đến lĩnh vực du lịch.

Nguồn số liệu sơ cấp được sử dụng trong nghiên cứu là kết quả lấy ý kiến đánh giá của 50 khách du lịch, 50 doanh nghiệp hoạt động trong lĩnh vực du lịch, 51 cán bộ quản lý Nhà nước về du lịch (với độ tin cậy $95 \%$ và sai số cho phép $\mathrm{e}= \pm 5 \%$ ). Nghiên cứu đã sử dụng thang đo Likert cho điểm từ 1 đến 5 để đánh giá các yếu tố thu hút đầu tư vào lĩnh vực $\mathrm{du}$ lịch của tỉnh Tuyên Quang.

Phương pháp chính được sử dụng để phân tích số liệu là phương pháp thống kê so sánh và thống kê mô tả dựa trên phần mềm SPSS.

\section{Khái quát cơ sở lý luận về chiến lược marketing địa phương}

Theo Philip Kotler và cộng sự (2002), marketing địa phương là một thuật ngữ chỉ tập hợp các chương trình hành động hỗ trợ được địa phương thực hiện nhằm cải thiện khả năng cạnh tranh của địa phương và phát triển kinh tế. Hoạt động marketing sẽ tạo ra cho địa phương những đặc tính riêng biệt, một hình ảnh mới để kết hợp cùng với các yếu tố tự nhiên như vị trí địa lý, tài nguyên thiên nhiên từ đó nâng cao sức cạnh tranh và hấp dẫn đối với khách hàng của địa phương.

Marketing địa phương bao gồm 03 chủ thể chính đó là chính quyền, cộng đồng doanh nghiệp và công chúng.

Chính quyền và các cơ quan ban ngành chủ quản đóng vai trò chủ đạo trong việc ban hành và thực hiện các chính sách quy hoạch địa phương, xây dựng môi trường hấp dẫn cũng như tạo ra được sự uy tín cho sản phẩm của địa phương mình. Chủ thể tạo ra sản phẩm cho địa phương có sức hấp dẫn đối với khách hàng chính là cộng đồng doanh nghiệp, chủ thể này bên cạnh việc tạo việc làm, đóng góp 
cho ngân sách còn hỗ trợ chính quyền trong việc thực hiện các hoạt động dịch vụ công cộng. Tuy nhiên, mọi chủ trương, chính sách của chính quyền chỉ được thực hiện thành công khi có sự ủng hộ của người dân địa phương. Mặc dù không trực tiếp tham gia vào việc ban hành chương trình marketing địa phương nhưng lại gián tiếp hỗ trợ cho các hoạt động này được dễ dàng và thuận lợi hơn.

Khách hàng của marketing địa phương gồm 04 nhóm chính: khách du lịch, nhà đầu tư, cư dân - nhân công và thị trường xuất khẩu.

Họ là những người đem đến cho địa phương những lợi ích và giá trị nhất định như thu nhập từ các hoạt động dịch vụ, việc làm, vốn, khoa học công nghệ, trình độ chuyên môn. Vì vậy, địa phương cần phải đáp ứng những nhu cầu và mong muốn của khách hàng, cung cấp những dịch vụ, ưu đãi tốt nhất, môi trường sống an toàn, ổn định để thu hút và giữ chân khách hàng của mình. Để làm được điều này, các nhà marketing địa phương cần xác định và lựa chọn khách hàng mục tiêu trên cơ sở huy động và sử dụng hiệu quả nguồn lực của mình và cần thực hiện các chiến lược marketing địa phương. Theo Vũ Trí Dũng và Nguyễn Đức Hải (2011), chiến lược marketing địa phương bao gồm:

Chiến luợc marketing hình ảnh địa phuơng: Hình ảnh địa phương là tổng hợp những niềm tin, ý tưởng và ấn tượng về một địa phương. Trong bối cảnh các địa phương luôn cạnh tranh để thu hút khách hàng tiềm năng thì mỗi địa phương cần phải xây dựng một hình ảnh về địa phương mình độc đáo, riêng biệt, bền vững và phù hợp. Hình tượng địa phương phải có tính thuyết phục và phù hợp với thực trạng của địa phương đó. Hình tượng phải đơn giản, hấp dẫn và mang tính phân biệt cao, giúp tránh nhầm lẫn cho khách hàng mục tiêu.

Khi đã xây dựng được hình tượng cho địa phương, cần phải sử dụng các công cụ để thể hiện hình tượng đó. Có thể xây dựng và phát triển một khẩu hiệu mang tính mô tả và thuyết phục sau đó quảng bá hình ảnh qua nhiều kênh khác nhau. Đà Nẵng được biết đến với slogan "Fantasticity!" - thành phố tuyệt vời hay "Cát Bà - đảo ngọc tình người" là những khẩu hiệu đơn giản, hấp dẫn, nêu bật được những đặc trưng của địa phương, được quảng bá rộng rãi trên các phương tiện truyền thông và khách hàng có thể hình dung được những hình ảnh nổi bật nhất của các địa phương này.

Chiến luợc marketing đặc trung địa phương: Quảng bá hình ảnh không đủ để làm tăng tính hấp dẫn của địa phương. Khách hàng cần biết đến những địa điểm cụ thể, rõ ràng. Đó là những điểm nổi bật, hấp dẫn du khách, đây là những điểm dựa trên tài nguyên thiên nhiên, lịch sử để lại hay do chính địa phương tạo dựng lên. Bên cạnh đó, những hoạt động về văn hóa, đời sống người dân cũng là một điểm riêng tạo giá trị thu hút khách du lịch. Vịnh Hạ Long của Quảng Ninh là một ví dụ điển hình của marketing địa phương thông qua các thắng cảnh đẹp được công nhận là di sản thiên nhiên thế giới, Hà Nội với Hồ Gươm, Văn Miếu, Phú Thọ với Lễ hội đền Hùng... Để thực hiện tốt chiến lược này cần xây dựng các trung tâm hội thảo, tổ chức hội chợ với qui mô lớn để có thể thu hút lượng lớn khách hàng tiềm năng.

Chiến lược marketing cơ sở ha tầng: Cơ sở hạ tầng làm cho hình ảnh và sức hấp dẫn của địa phương tăng lên bao gồm đường giao thông, khu đô thị, chung cư, hệ thống điện nước và mạng lưới thông tin liên lạc. Địa phương có cơ sở hạ tầng đồng bộ, đặc biệt hệ thống công nghệ thông tin phát triển sẽ là ưu thế lớn so với các địa phương khác trong thu hút khách hàng. Đà Nẵng là một ví dụ điển hình trong việc thực hiện thành công chiến lược marketing cơ sở hạ tầng. Khách du lịch có thể đến Đà Nẵng bằng cả bốn loại hình phương tiện giao thông bao gồm đường bộ, đường sắt, đường thủy và đường hàng không. Chính quyền thành phố đã kêu gọi đầu tư và ban hành chính sách khuyến khích thu hút đầu 
tư vào hạ tầng đã tạo cho Đà Nẵng một hệ thống các khu nghỉ mát, khách sạn, trung tâm mua sắm, trung tâm văn hóa, sân golf... thỏa mãn nhu cầu ngày càng cao của du khách.

Chiến lược marketing con người: Đó là hoạt động quảng bá địa phương qua những nhân vật nổi tiếng, những nhà lãnh đạo có uy tín, nhân tài, những người có tinh thần khởi nghiệp hay những người đã chuyển đến địa phương. Thông qua hoạt động marketing con người, hình ảnh địa phương cũng sẽ được nhắc tới qua tính cách người dân, phong tục, tập quán, đặc tính hấp dẫn, điều kiện và môi trường sống.

Theo Phan Thế Công (2015), trong lĩnh vực du lịch để thực hiện hiệu quả chiến lược marketing con người thì điều đầu tiên và quan trọng nhất là phải nâng cao chất lượng nguồn nhân lực du lịch. Chính những người làm du lịch sẽ là những người quan hệ trực tiếp và tác động mạnh mẽ tới khách hàng. Các địa phương có thể tiến hành điều tra và đánh giá lại nguồn nhân lực về du lịch từ đó đưa ra những giải pháp phù hợp nhất để nâng cao chất lượng của đội ngũ này.

3. Thực trạng marketing địa phương nhằm phát triển du lịch tại tỉnh Tuyên Quang

Trong những năm gần đây, ngành du lịch tỉnh Tuyên Quang đã đạt được những kết quả và thành tựu nhất định. Số lượng khách du lịch đến Tuyên Quang tăng cao, từ 603.000 lượt khách năm 2011 lên đến 1.309.000 lượt khách năm 2015, bình quân mỗi năm tăng 21,38\%. Điều này cho thấy, lượng khách du lịch tới Tuyên Quang tăng khá nhanh và đều qua các năm. Tuy nhiên khách du lịch đến Tuyên Quang chủ yếu là khách trong nước với mức tăng bình quân mỗi năm là $21,79 \%$, khách nước ngoài chiếm tỷ lệ nhỏ và giảm dần qua các năm, đa số đến từ Trung Quốc và Hàn Quốc. Doanh thu từ du lịch là 552.000 triệu đồng năm 2011, tới năm 2015 đạt 1.135 .000 triệu đồng, tăng bình quân 19,74\% mỗi năm. Theo thống kê của Sở Văn hóa, Thể thao và Du lịch tỉnh Tuyên Quang, năm 2015 toàn tỉnh có 262 cơ sở lưu trú (tăng 125 cơ sở lưu trú so với năm 2011) và 06 doanh nghiệp lữ hành.

Bảng 1: Thục trạng phát triển du lịch tỉnh Tuyên Quang giai đọ̣n 2011 - 2015

\begin{tabular}{|c|c|c|c|c|c|c|c|}
\hline & : & 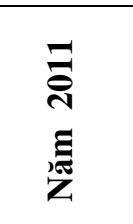 & 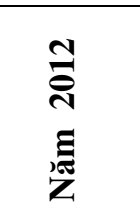 & 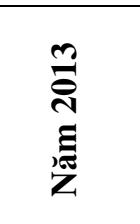 & 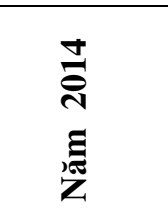 & 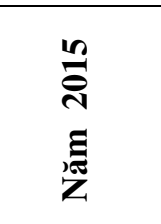 & $\begin{array}{c}\text { Tốc độ } \\
\text { phát triển } \\
\text { bình quân } \\
\text { (\%) }\end{array}$ \\
\hline Khách trong nước & $\begin{array}{l}\text { Lượt } \\
\text { người }\end{array}$ & 592.000 & 718.000 & 849.990 & 1.009 .100 & 1.302 .700 & 121,79 \\
\hline Khách quốc tế & $\begin{array}{l}\text { Lượt } \\
\text { người }\end{array}$ & 11.000 & 12.000 & 10.410 & 5.900 & 6.300 & 86,99 \\
\hline Tổng & $\begin{array}{l}\text { Lượt } \\
\text { người }\end{array}$ & 603.000 & 730.000 & 860.400 & 1.015 .000 & 1.309 .000 & 121,38 \\
\hline $\begin{array}{l}\text { Tổng thu } \\
\text { du lịch }\end{array}$ & $\begin{array}{l}\text { Triệu } \\
\text { đồng }\end{array}$ & 552.000 & 602.000 & 880.000 & 908.000 & 1.135 .000 & 119,74 \\
\hline
\end{tabular}

(Nguồn: Sở Văn hóa, Thể thao và Du lịch tỉnh Tuyên Quang) 
Các hoạt động trong lĩnh vực du lịch đều đã có sự đầu tư, quan tâm của Chính quyền thông qua các cơ chế, chính sách ưu đãi, hỗ trợ, chương trình quảng bá nhằm thu hút khách du lịch và nhà đầu tư. Tuy nhiên, các hoạt động này chỉ mang tính thời điểm, đối tượng tác động chưa đầy đủ và đặc biệt là chưa có một chiến lược cụ thể, rõ ràng, chưa xây dựng được chiến lược marketing địa phương.

Nhận thức được tầm quan trọng của việc quảng bá hình ảnh, Trung tâm xúc tiến đầu tư phối hợp với các đơn vị quản lý Nhà nước về du lịch đã thực hiện các hoạt động quảng bá, xúc tiến đầu tư thông qua các hoạt động liên kết, hợp tác phát triển du lịch với các tỉnh, thành phố trong nước và quốc tế, quảng bá hình ảnh, tiềm năng thế mạnh, danh mục dự án đầu tư của tỉnh trên các phương tiện thông tin đại chúng. Tuy nhiên, việc quảng bá chỉ mang tính chung chung, chưa có điểm nhấn, chưa gây được ấn tượng với khách hàng.

Hiện tại, du lịch Tuyên Quang chưa có biểu tượng cũng như slogan chính thức. Các điểm du lịch nổi tiếng như suối khoáng Mỹ Lâm, khu du lịch sinh thái Nà Hang, khu di tích quốc gia đặc biệt Tân Trào có những câu khẩu hiệu nhưng mức độ sử dụng rất hạn chế và không được quảng bá rộng rãi. Qua kết quả điều tra khách du lịch, 46\% đánh giá hoạt động quảng bá hình ảnh mới chỉ ở mức trung bình, $26 \%$ cho rằng ở ở mức kém. Hình ảnh được biết tới nhiều nhất đó là cây đa Tân Trào, cần phải xây dựng và phát triển thêm các hình ảnh mới, tránh sự nghèo nàn, mờ nhạt trong định vị hình ảnh.

Hình 1: Mức độ quảng bá hình ảnh du lịch tại tỉnh Tuyên Quang

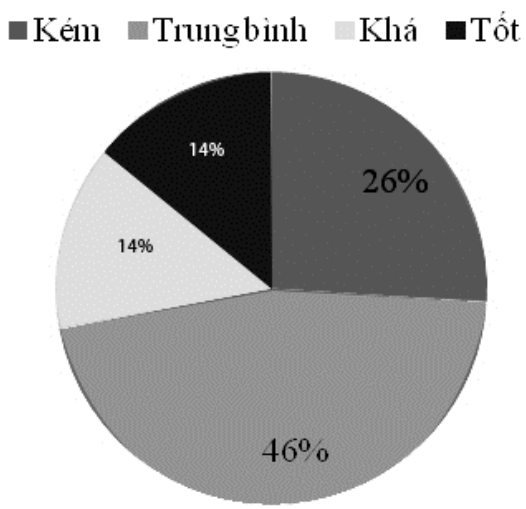

(Nguồn:Tổng hợp tù các số liệu qua điều tra)

Để phát triển du lịch, tỉnh Tuyên Quang đã có bước tiến mới trong việc mở rộng các loại hình du lịch như du lịch văn hóa - lịch sử, du lịch sinh thái, du lịch tâm linh, du lịch lễ hội dựa trên những tài nguyên du lịch đã có và mới được hình thành. Các khu, điểm du lịch thu hút được lượng lớn khách du lịch như khu di tích Quốc gia đặc biệt Tân Trào, khu nghỉ dưỡng suối khoáng Mỹ Lâm, khu du lịch sinh thái Nà Hang, các đền, chùa nổi tiếng như đền Hạ, chùa An Vinh, đền Cảnh Sanh, chùa Hang, đền Minh Lương. Bên cạnh đó, nhiều loại hình du lịch mới được phát triển và hình thành cũng đã tạo nên đặc trưng riêng biệt cho du lịch Tuyên Quang như lễ hội Thành Tuyên, lễ hội Rước Mẫu, lễ hội Lồng Tông.

Có thể thấy, du lịch Tuyên Quang có rất nhiều đặc trưng nổi bật riêng có. Tuy nhiên, việc đầu tư vào các điểm du lịch quy mô nhỏ, thực trạng đầu tư manh mún, nhỏ lẻ, chạy theo số lượng. Nguyên nhân của tình trạng trên là do quy hoạch du lịch tổng thể, chi tiết chưa được thực hiện tốt và việc quảng bá các đặc trưng còn thiếu tính chuyên nghiệp, đồng bộ.

Để đẩy mạnh phát triển du lịch, tỉnh Tuyên Quang đã ban hành Quyết định số 25/2007/QĐ-UBND ngày14/8/2007 của Uỷ ban Nhân dân tỉnh Tuyên Quang về việc ban hành Quy định chính sách khuyến khích ưu đãi đầu tư trên địa bàn tỉnh Tuyên Quang. Đây là tín hiệu tốt, thể hiện sự quyết tâm của Chính quyền trong việc thu hút các nhà đầu tư, đặc biệt vào lĩnh vực du lịch. Tuy nhiên, kết quả điều tra 50 doanh nghiệp hoạt động trong lĩnh vực du lịch về các yếu tố thu hút đầu tư của tỉnh Tuyên Quang theo thang điểm từ 1 đến 5 (1 - Kém, 2 - Trung bình, 3 - Khá, 4 - Tốt, 5 Rất tốt) các doanh nghiệp đánh giá cao về thị trường $\mathrm{du}$ lịch tiềm năng với mức đánh giá bình quân là 4,1176, chính sách pháp luật và hoạt động thúc đẩy hỗ trợ kinh doanh mức đánh giá bình quân lần lượt là 3,0784; 3,0392. Cơ sở hạ tầng với mức đánh giá ở mức thấp nhất là 2,3725 . Điều này cho thấy, sự yếu kém 
của hệ thống cơ sở hạ tầng cản trở việc thu hút và giữ chân các nhà đầu tư, mặc dù tỉnh đã ban hành các văn bản khuyến khích và mức ưu đãi đầu tư trong lĩnh vực du lịch tuy nhiên khi đưa vào thực hiện thì vẫn còn nhiều vướng mắc như thông tin về mức ưu đãi, thủ tục hành chính gây cản trở trong quá trình đầu tư của doanh nghiệp. Vì vậy, trong giai đoạn 2011 2015, chỉ có 11 dự án đã và đang triển khai thực hiện với tổng số vốn đầu tư 416.300 triệu đồng và chưa có dự án nào được thực hiện từ nguồn vốn đầu tư trực tiếp nước ngoài. Các dự án này chiếm một con số rất nhỏ so với các ngành khác như xây dựng, vận tải, thông tin liên lạc hay công nghiệp chế biến.

Hình 2: Lý do các nhà đầu tư vào tỉnh Tuyên Quang trong lĩnh vục du lịch

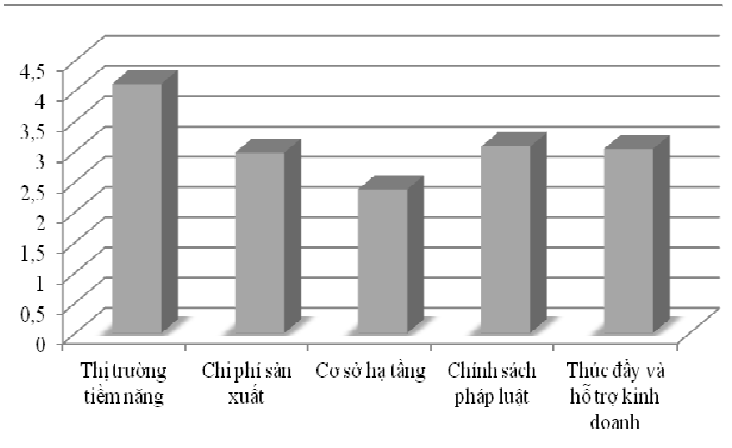

(Nguồn:Tổng hợp tù các số liệu qua điều tra)

Được đánh giá là tỉnh có nguồn lực lao động dồi dào, tuy nhiên số lượng và chất lượng nguồn lực lao động làm việc trong lĩnh vực du lịch chiếm tỷ lệ nhỏ, còn kém về mặt chất lượng. Với câu hỏi "Chất lượng nguồn nhân lực trong ngành du lịch của tỉnh Tuyên Quang hiện nay như thế nào?”, tác giả thu được kết quả từ 51 phiếu đánh giá của lãnh đạo, cán bộ làm việc trong các cơ quan quản lý liên quan đến lĩnh vực du lịch như sau: nguồn nhân lực du lịch tỉnh Tuyên Quang hiện nay đạt mức trung bình với 56,9\% tức 29/51 phiếu điều tra. Tiếp theo là ở mức kém với $23,5 \%$ tức 12/51 phiếu điều tra và cuối cùng là ở mức khá 19,6\% tức 10/51 phiếu điều tra. Đây là một hạn chế rất lớn của ngành du lịch địa phương, điều này cho thấy sự phát triển của nguồn nhân lực cần phải được quan tâm, chú trọng nhiều hơn nữa để xứng với tiềm năng và thế mạnh du lịch, góp phần phát triển ngành du lịch tỉnh Tuyên Quang.

Mặc dù đạt được những kết quả khả quan nhưng du lịch Tuyên Quang vẫn còn hạn chế, xét trên góc độ marketing địa phương, đó là:

Thứ nhất, định vị hình ảnh du lịch chưa rõ ràng, sản phẩm du lịch còn nghèo nàn, chưa có điểm nhấn.

Thư hai, chính sách và hoạt động xúc tiến đầu tư chưa chuyên nghiệp, chưa hiệu quả, dẫn đến không tạo được sức hút đối với khách du lịch và nhà đầu tư.

Thư $b a$, thiếu quy hoạch phát triển bền vững.

Thứ tu, phát triển mạng lưới cơ sở lưu trú, giao thông vận tải còn thiếu đồng bộ, thiếu dịch vụ bổ sung, hỗ trợ cho du khách.

Thứ năm, nguồn nhân lực cho ngành du lịch còn thiếu và chất lượng thấp.

\section{Xây dụng chiến lược marketing địa phương nhằm phát triển du lịch cho tỉnh Tuyên Quang}

Trên cơ sở lý thuyết về marketing địa phương và thực trạng marketing địa phương phát triển du lịch của tỉnh Tuyên Quang, có thể đưa ra một số gợi ý chiến lược marketing địa phương nhằm phát triển tại tỉnh Tuyên Quang như sau:

\subsection{Chiến lược marketing hình ảnh địa phương}

Nhắc đến Tuyên Quang, du khách sẽ biết tới Tân Trào - thủ đô khu giải phóng. Đây là hình ảnh định vị đã được công nhận trong quá khứ, Tuyên Quang cần tiếp tục nâng cao giá trị và phát huy hình ảnh này. Tuy nhiên, nếu chỉ có duy nhất một hình ảnh, du khách sẽ không thể biết đến những điểm du lịch hấp dẫn khác. Để tạo được ấn tượng trong lòng khách du lịch cần xây dựng hình tượng địa phương thật hấp dẫn, độc đáo, không quá nâng cao hình ảnh không đúng với sự thực, điều này sẽ làm mất lòng tin của khách du lịch và nhà đầu tư.

Có thể tổ chức cuộc thi thiết kế biểu 
tượng và slogan cho du lịch Tuyên Quang hoặc thuê công ty nước ngoài thực hiện việc này. Đây là cách làm của nhiều tỉnh, thành phố trong nước và đem lại hiệu quả rất tích cực. Khi giới thiệu về hình ảnh Tuyên Quang có thể sử dụng khẩu hiệu "Tuyên Quang - miền sơn cước" nói lên mảnh đất tươi đẹp, hoang sơ, hùng vĩ bên cạnh những địa danh lịch sử nổi tiếng thì thiên nhiên ban tặng cho nơi đây những cảnh quan làm mê hoặc lòng người. Mỗi một địa danh du lịch có thể có khẩu hiệu riêng của mình như "Na Hang - Hạ Long trên cạn”, “Tuyên Quang - thành phố trẻ”.

Sau khi đã xây dựng được hình ảnh địa phương, cần phải được quảng bá rộng rãi trên các phương tiện thông tin truyền thông. Bên cạnh việc quảng bá theo cách truyền thống qua báo, tạp chí, truyền hình thì cần quảng bá qua các trang web, mạng xã hội, diễn đàn vì đây là kênh quảng bá nhanh chóng và rộng rãi nhất đến tất cả mọi đối tượng. Một công cụ nữa cũng có tác dụng quảng bá hình ảnh nhanh chóng và để lại ấn tượng lâu dài là làm phim truyền hình hoặc clip ngắn thật hay với bối cảnh tại Tuyên Quang, cách làm này sẽ giúp cho khách du lịch biết đến và muốn tới chiêm ngưỡng những cảnh đẹp được thể hiện trên phim hay đoạn clip ngắn.

\subsection{Chiến lược marketing đặc trưng địa phương}

Tuyên Quang có nhiều di tích lịch sử nổi tiếng, ghi đậm dấu ấn trong lòng du khách, đặc biệt là lán Nà Lừa, đình Hồng Thái, cây đa Tân Trào, Kim Bình. Tới đây, khách du lịch ngoài thăm quan các di tích còn được tìm hiểu những nét sinh hoạt văn hóa đa dạng mang đậm bản sắc văn hóa Việt Bắc. Là tỉnh có 22 dân tộc anh em sinh sống, nên đời sống văn hóa vô cùng phong phú được thể hiện qua các Lễ hội Lồng Tông, Nghi lễ hát Then của người Tày, Lễ Cấp sắc và làn điệu Páo dung của người Dao Tuyên Quang đã được Bộ Văn hóa - Thể thao và Du lịch công nhận là Di sản văn hóa phi vật thể quốc gia.

Bên cạnh hệ thống giá trị văn hóa vật thể độc đáo, tỉnh Tuyên Quang còn nổi tiếng với những điểm du lịch tâm linh: Đền Hạ, đền Mẫu Ỷ La, đền Cảnh Xanh, đền Thượng, chùa An Vinh. Các điểm du lịch sinh thái - nghỉ dưỡng hấp dẫn như: khu du lịch sinh thái $\mathrm{Na}$ Hang, Hàm Yên, Núi Dùm, suối khoáng Mỹ Lâm, danh thắng thác Bản $\mathrm{Ba}$, quần thể Động Tiên. Đặc biệt, khu du lịch sinh thái Na Hang, tới đây du khách được đi du thuyền trên lòng hồ thuỷ điện Tuyên Quang, ghé thăm thác Pắc Ban (thác $M o ̛$ ) được xếp hạng là thắng cảnh Quốc gia, khu bảo tồn thiên nhiên Tát Kẻ Bản Bung là cánh rừng nguyên sinh của $\mathrm{Na}$ Hang có cây nghiến nghìn năm tuổi và loài Voọc mũi hếch được ghi trong sách đỏ thế giới. Na Hang còn được biết đến với những đặc sản như rượu Ngô, rượu Đao, lẩu cá Lăng, cá Nheo, xôi ngũ sắc.

Như vậy, các yếu tố lịch sử và tài nguyên thiên nhiên đã đem đến cho Tuyên Quang những lợi thế thuận lợi cho việc xây dựng đặc trưng của địa phương: Tân Trào - thủ đô khu giải phóng, lễ hội Lồng Tông, nghi lễ hát Then, $\mathrm{Na}$ Hang - quần thể du lịch sinh thái mang tầm cỡ quốc gia mà ít nơi có được.

Ngoài ra, cần xây dựng và quảng bá một số đặc trưng của địa phương như:

(1) Lễ hội thành Tuyên - lễ hội đặc sắc vào mỗi dịp trung thu, trở thành thương hiệu riêng có của Tuyên Quang, được sách kỷ lục Guiness Việt Nam xác nhận là lễ hội có nhiều mô hình đèn lớn nhất Việt Nam.

(2) Du lịch homestay tại các làng văn hóa như Làng Văn hóa - Du lịch Tân Lập xã Tân Trào (Sơn Dương), Làng văn hóa Giếng Tanh, xã Kim Phú (Yên Sơn), Làng văn hóa dân tộc Dao xã Bình Xa (Hàm Yên). Thích hợp cho những du khách yêu thích và khám phá đời sống, văn hóa của các dân tộc Tuyên Quang.

\subsection{Chiến lược maketing cơ sở hạ tầng}

Cơ sở hạ tầng kỹ thuật là yếu tố quan trọng trong việc phát triển du lịch. Hiện nay cơ sở hạ tầng là điểm yếu của tỉnh Tuyên Quang, cần phải rà soát lại quy hoạch cơ sở hạ tầng, 
đầu tư nâng cấp và cải tạo mới. Thực hiện chiến lược marketing cơ sở hạ tầng, sẽ tạo môi trường thuận lợi cho nhà đầu tư, phục vụ nhu cầu của khách du lịch. Cụ thể:

(1) Trong quy hoạch phát triển giao thông quốc gia, Tuyên Quang sẽ có hệ thống giao thông hoàn chỉnh gồm đường bộ, đường thuỷ, đường sắt tạo điều kiện phá vỡ thế yếu về vị trí địa lý.

(2) Tuyến đường cao tốc Nội Bài - Lào Cai đưa vào sử dụng, việc di chuyển từ Hà Nội tới Tuyên Quang bằng ô tô rút ngắn thời gian chỉ còn 3 giờ so với 4 - 5 giờ như trước đây.

(3) Các tuyến đường liên tỉnh, nội địa đều được đầu tư mở rộng, nâng cấp có khả năng đáp ứng tốt cho việc vận chuyển hàng hóa và tham quan du lịch. Triển khai đầu tư xây dựng 11 bến xe, một số điểm đỗ, dừng xe tại trung tâm các huyện, thành phố và các thị trấn, đưa vào hoạt động các tuyến xe bus.

(4) Đầu tư hiện đại hóa hệ thống thông tin liên lạc đã được triển khai và hoàn thiện.

(5) Các cơ sở lưu trú nâng cấp hệ thống phục vụ du khách, đầu tư xây dựng nhiều khách sạn từ 2 - 4 sao như Khách sạn Royal Place, Mường Thanh, Mai Sơn,...

(6) Xây dựng các siêu thị, chợ phục vụ nhu cầu du khách. Thời gian tới, trung tâm thương mại Vincom sẽ được xây dựng tại thành phố Tuyên Quang.

Tất cả những yếu tố này sẽ tạo nên được một hệ thống đồng bộ, hiện đại, phù hợp, đáp ứng nhu cầu của khách du lịch cũng như các nhà đầu tư.

\subsection{Chiến lược marketing con người}

Người dân Tuyên Quang đa số là người dân tộc, làm nông nghiệp nên bản tính thật thà, chất phác, thân thiện, cởi mở và mến khách. Đây chính là yếu tố góp phần làm tăng sức hấp dẫn của du lịch Tuyên Quang. Để phát huy yếu tố con người, tinh Tuyên Quang cần phải thực hiện:

(1) Nâng cao nhận thức được tầm quan trọng và lợi ích của du lịch đối với người dân.
Từ đó, người dân địa phương sẽ tích cực tham gia xây dựng các làng văn hóa - du lịch, làng nghề, tham gia khôi phục, phát triển các lễ hội mang đậm bản sắc văn hóa truyền thống, tham gia sản xuất hàng hóa, hàng lưu niệm để phục vụ phát triển du lịch.

(2) Thường xuyên mở các lớp tập huấn nghiệp vụ tại địa phương hoặc cử cán bộ đi học nâng cao tại những cơ sở đào tạo du lịch uy tín nhằm nâng cao chất lượng đội ngũ cán bộ ngành du lịch, đáp ứng tốt cho công tác quản lý, hỗ trợ cho các hoạt động du lịch, đặc biệt là các cán bộ xúc tiến đầu tư.

(3) Phát huy vai trò của trường Đại học Tân Trào trong việc đào tạo nguồn nhân lực cho ngành du lịch Tuyên Quang. Chất lượng lao động qua đào tạo sẽ tăng, đáp ứng các nhu cầu của các cơ sở lữ hành, kinh doanh dịch vụ du lịch.

\section{Biện pháp tổ chức thực hiện chiến lược marketing địa phương nhằm phát triển du lịch tại tỉnh Tuyên Quang}

Để thực hiện thành công chiến lược marketing địa phương nhằm phát triển du lịch, tỉnh Tuyên Quang cần thực hiện các biện pháp sau:

Thư nhất, rà soát lại quy hoạch phát triển du lịch. Tuyên Quang hiện nay phát triển du lịch chủ yếu dựa trên tài nguyên sẵn có, quy hoạch hiện nay chưa thực sự tương xứng với tiềm năng và lợi thế của tỉnh. Vì vậy, cần phải rà soát lại quy hoạch để Tuyên Quang trở thành một tỉnh phát triển du lịch bền vững.

Thư hai, rà soát, điều chỉnh, bổ sung và hoàn chỉnh những nội dung trong các quyết định ban hành về cơ chế, chính sách ưu đãi đầu tư trong lĩnh vực du lịch từ đó tạo môi trường thuận lợi, nâng cao uy tín đối với các nhà đầu tư. Đặc biệt, cần ưu đãi đối với các dự án đầu tư vào cơ sở hạ tầng, vì hiện nay hệ thống cơ sở hạ tầng đang là điểm yếu của Tuyên Quang.

Thứ $b a$, tăng cường năng lực quản lý Nhà nước về du lịch, thực hiện quản lý và kiểm soát hoạt động du lịch, đẩy mạnh huy động và quản 
lý sử dụng các nguồn lực đảm bảo thực hiện các hoạt động marketing địa phương.

Thư tur thực hiện tốt các biện pháp giám sát, đánh giá thực hiện các hoạt động marketing địa phương, tăng cường trách nhiệm của các cơ quan, các cấp, các ngành liên quan.

Thứ năm, đề nghị các Bộ, ngành quan tâm đến tỉnh Tuyên Quang trong việc vận động và kêu gọi các nhà tài trợ đầu tư nhằm phát triển du lịch. Hỗ trợ trong công tác xúc tiến đầu tư, quảng bá hình ảnh của tỉnh đến với bạn bè trong nước và quốc tế.

\section{Kết luận}

Tuyên Quang có nhiều tiềm năng và lợi thế cho phát triển du lịch, mặc dù đã được định hướng và quan tâm nhưng ngành du lịch
Tuyên Quang vẫn chưa đạt được những kết quả tương xứng. Nắm bắt kinh nghiệm của các địa phương thành công trong lĩnh vực du lịch, cùng với thực trạng du lịch hiện nay, Tuyên Quang cần phải có chiến lược marketing địa phương cụ thể. Kết quả nghiên cứu chỉ ra rằng, việc thực hiện chiến lược marketing địa phương sẽ giúp Tuyên Quang định vị được hình ảnh, đặc trưng của địa phương, phát triển được cơ sở hạ tầng cũng như nguồn nhân lực du lịch từ đó đáp ứng các nhu cầu và mong muốn của khách hàng mục tiêu. Để các chiến lược này thành công, chính quyền tỉnh Tuyên Quang cần phải có quan điểm toàn diện về marketing địa phương cũng như sự phối hợp chặt chẽ giữa các chủ thể đó là chính quyền, người dân và cộng đồng doanh nghiệp.

\section{TÀI LIỆU THAM KHẢO}

1. Phan Thế Công (2015), Xây dựng chiến lược marketing địa phương cho đảo Phú Quốc, Tạp chí Khoa học và Công nghệ, Đại học Công nghiệp Hà Nội, số 31, trang 93 - 97;

2. Vũ Trí Dũng và Nguyễn Đức Hải (2011), Marketing lãnh thổ, Nxb Đại học Kinh tế quốc dân;

3. Vũ Trí Dũng, Nguyễn Quang Vinh (2013), "Xây dựng chiến lược marketing địa phương nhằm thu hút khách du lịch đến với quần đảo Cát Bă”, Tạp chí nghiên cứu Kinh tế, (số 424);

4. Nguyễn Thị Thống Nhất (2010), Chiến lược Marketing dịa phương nhằm thu hút khách du lịch đến thành phố Đà Nã̃ng, Tạp chí Khoa học và Công nghệ, Đại học Đà Nẵng, số 5 (40), trang 215-224;

5. Philip Kotler, et al (2002), Marketing Asian Places, Singapore. 